\title{
Resenha
}

\section{Ser ou não ser um artífice - uma questão para a Saúde do Trabalhador?}

To be or not to be a craftsman - a question for Workers' Health?

SENNETT, Richard. O artífice. Tradução Clóvis Marques. Rio de Janeiro: Record, 2009. 360p.

Em $O$ artífice, publicado pela Editora Record em 2009, Richard Sennett dá continuidade a um projeto iniciado na década de 1990, quando se voltou para o entendimento do novo mundo do trabalho. A corrosão do caráter (SENNETT, 1998) foi o primeiro passo desse projeto e, neste, Sennett buscou demonstrar como a ética do capitalismo "flexível" afeta negativamente o ser humano, corroendo as relações e o caráter. Em 2002, ele publicou Respect in a world of inequality, onde trata das relações sociais no mundo capitalista (SENNETT, 2002). Em 2006, no livro A cultura do novo capitalismo, delineia as mudanças ocorridas entre as formas anteriores de capitalismo e a forma atual (global e flexível) e seu impacto sobre os valores pessoais e sobre os modos de viver dentro e fora das organizações (SENNETT, 2006).

Professor e sociólogo formado nas Universidades de Chicago e de Harvard, Richard Sennett publicou outras obras de interesse sociológico e incluiu em seu currículo, também, livros de ficção (SENNETT, 2008).

Na presente obra, o autor dá um tom mais positivo às suas análises. O texto centra-se na "habilidade artesanal" definida por ele como "[...] um impulso humano básico e permanente, o desejo de um trabalho benfeito [sic] por si mesmo" (p. 19). Para falar desta habilidade natural para o trabalho, Sennett divide o texto em três partes: artífices, artesanato e habilidade artesanal, que por sua vez se subdividem em 10 capítulos, incluindo, ainda, o prólogo e a parte conclusiva.

Já no prólogo o autor tenta explicar para o leitor quando lhe surgiu o "incômodo" em relação à temática do livro. Segundo ele, nas discussões com Hannah Arendt, sua mestra, as questões sobre o homem e sua práxis trouxeram-lhe não só explicações, mas dúvidas. Dúvidas que se centraram no "por que" e no "como" fazemos as coisas.

No capítulo 1, denominado de $O$ artífice inquieto, Sennett define o que considera "Artífice": o trabalho prático, artesanal que requer do seu executor o desenvolvimento de habilidades e competências diversas. A busca de soluções para os problemas com os quais se depara no trabalho reafirma a vinculação entre o fazer e o pensar, seja o Artífice um carpinteiro ou um regente de orquestra. O que o torna um Artífice é, principalmente, uma "condição humana especial": o engajamento. Numa linguagem culta e inteligente, remetendo o leitor ao passado e ao tempo presente, nesse capítulo, ele busca responder como ocorre este engajamento e para isso faz uma crítica às práticas "motivacionais" que incentivam a competição, aos avanços tecnológicos que em nome da capacitação impedem a construção do savoir-faire por parte dos trabalhadores e às medidas conflitantes de desempenho (qualidade x quantidade), divergentes do trabalho do Artífice.

No capítulo 2, o autor descreve espaços de trabalho diferenciados (guildas medievais, ateliês e oficinas) onde atuam os Artífices. Demonstra que estes espaços sociais de trabalho organizam-se sob diferentes normas, padrões de desempenho, formas de relacionamento e de autoridade, sendo esta forma de organização do trabalho responsável pela motivação. Suas análises coadunam-se com as proposições da Psicologia Organizacional do Trabalho e da Ergonomia que enfatizam a importância de se conhecer a organização do trabalho, que interfere não só na realização da atividade de trabalho, mas também nos sentimentos a ele vinculados. Mais do que a motivação, Sennett considera que a forma como é organizado o trabalho pode favorecer (no caso das guildas) ou não (no caso dos ateliês e das oficinas de fabricação de violinos Stradivari e Guarneri) a transferência do conhecimento, bem como dar à atividade de trabalho um caráter coletivo. Segundo ele, a ênfase nos aspectos ligados à "originalidade" da obra, presente nos ateliês e nas oficinas, rompeu com o caráter coletivo, favorecendo a centralização e a não disseminação do conhecimento.

Máquinas é o título do terceiro capítulo e nele o autor leva o leitor a viajar pelo tempo do Iluminismo. O "projeto Iluminista" parece ir ao encontro da concepção materialista de Sennett. A Enciclopédia de Diderot é utilizada para revelar os sentimentos e as concepções deste período em relação às mudanças ocorridas no mundo, principalmente àquelas relativas ao trabalho e ao surgimento das máquinas. As análises sobre a enciclopédia o levam a pensar que os Iluministas estabeleciam uma relação positiva com as máquinas que começavam a surgir. Dois conceitos são importantes para compreender as discussões delineadas pelo autor no transcorrer do capítulo: replicantes e robôs. Sennett os denomina como ferramentas-espelho na medida em que levam o homem a pensar sobre si mesmo. O replicante refere-se à máquina que complementa alguma função humana; o robô, diferentemente do anterior, amplia, em muito, determinada capacidade, levando o homem a deparar-se com seus limites. O robô, ao levar o homem a deparar-se com o seu limite, pode fortale- 
cê-lo, levando-o ao desenvolvimento de novos talentos. Isto é denominado por ele como o "fracasso salutar". É salutar, portanto, que o Artífice aceite a máquina e encare a sua imperfeição, pois a obsessão pela perfeição pode levá-lo à desmotivação.

No quarto capítulo, Richard Sennett descreve o que ele entende por Consciência material. Para ele, todos os Artífices dispõem de uma consciência material. Com esta afirmação, deseja demonstrar que a consciência das coisas (as ideias, as representações e os pensamentos) não está desvinculada das coisas em si. O mundo material objetivo está interligado e influencia o mundo das ideias. Para o Artífice, isso significa que a sua consciência material tem afinidade com a sua atividade de trabalho, é, ainda, uma consciência engajada: o Artífice é curioso, é interessado no que pode ser modificado em seu trabalho. No restante do capítulo, o autor se detém a descrever, por meio de exemplos (do oleiro, da fabricação de tijolos), diferentes formas de consciência material. Cabe mencionar, contudo, a forma de consciência material denominada por Sennett como "presença": é a marca pessoal deixada pelo trabalhador no seu trabalho. Por meio de especificidades na fabricação (de tijolos, por exemplo), ele (o Artífice tijoleiro) confirmava sua existência. Não por meio de uma assinatura, mas por meio de símbolos ou de peculiaridades que dava ao produto de seu trabalho. Fazer isso dava-lhe sustentação, afirmando sua presença no mundo.

Na segunda parte de sua obra, denominada "Artesanato", conforme ele mesmo descreve: passa “[...] a tratar das maneiras como o Artífice adquire e desenvolve atividades físicas específicas para fazê-lo" (p. 165). Inicia, assim, analisando A mão e sua relação com o cérebro, no quinto capítulo. Exemplos de atividades artesanais dos músicos, dos cozinheiros e de insufladores de vidro são utilizados pelo autor na busca de objetivar suas afirmações. O que, no entanto, é utilizado para dar qualidade e clareza ao texto - o detalhamento, a análise minuciosa de exemplos - pode dispersar o leitor desavisado, fazendo-o afastar-se do foco central das discussões oferecidas pelo autor.

Além de demonstrar como o desenvolvimento das mãos, dos movimentos de apreensão e das habilidades do toque foi importante para o desenvolvimento do pensamento, não mera consequência do cérebro sobre o corpo, o capítulo traz uma importante reflexão sobre a forma de lidar com o erro e sua relação com o desenvolvimento de habilidades manuais. Para Sennett é possível aprender conhecendo a técnica, mas esta aprendizagem está intimamente ligada à disposição de experimentar por meio do erro. A aprendizagem da técnica envolve também a repetição, não uma repetição fragmentada e mecanizada de ações, mas uma repetição que permita ao Artífice tomar consciência das coisas. Nesta tomada de consciência, torna-se possível aprimorar seu autocontrole, utilizar de forma adequada e equilibrada suas forças e habilidades, sincronizar corpo e mente e concentrar-se naquilo que faz de forma a envolver-se emocionalmente e intelectualmente com sua atividade.
No capítulo seguinte, O princípio da instrução, mostre, em vez de dizer, a questão da aprendizagem continua sendo foco. Agora, entretanto, o autor irá tratar uma das formas utilizadas pelos mestres ou especialistas para ensinar: os manuais. Ele apresenta as dificuldades existentes na linguagem de manuais elaborados por especialistas, que tentam ensinar ao principiante o "como fazer". Considera que, assim como na oficina é relevante que o mestre não só diga como, mas demonstre por meio de atos os procedimentos corretos, em um manual esta máxima também deve ser considerada. Utilizando como exemplo uma receita culinária, Sennett destaca que um manual deve orientar e antecipar as dificuldades do aprendiz, demonstrar simpatia (colocando-se no lugar de quem aprende) e instruir de forma expressiva.

Do ponto de vista material, as pequenas coisas ganham grandes significações. No sétimo capítulo, esta visão é identificada na análise que o autor faz das ferramentas. Mais do que mero objeto, Sennett considera que os instrumentos estimulam o pensar. Muitas vezes, sua própria limitação leva o artífice a reinventar seus usos, descobrindo novas aplicações, por isso, o nome do capítulo Ferramentas estimulantes. Um aspecto relevante a ser destacado é que esta reinvenção não ocorre somente pelo acaso, pelo imprevisível. É o savoir-faire, o conhecimento acumulado pelo artífice que permite a ele fluir a imaginação e a criatividade, autorizando-o a questionar e a modificar o uso das coisas.

A forma como o Artífice deve lidar com as dificuldades e imprecisões - Resistência e ambiguidade - que se impõem na realização de sua atividade é a temática do capítulo 8. O autor apresenta, como exemplo de modos diferenciados de lidar com a resistência, o trabalho de dois engenheiros urbanos, que encararam dificuldades semelhantes na construção de túneis sob o rio Tâmisa. Por meio destes, Sennett demonstra que o bom Artífice não somente tenta combater a resistência, mas, mais do que isto, ele apresenta condutas pró-ativas e formas de pensar que rompem com a tentativa de enfrentamento e que permitem a ele reconfigurar o problema.

Na terceira parte de sua obra, Habilidade Artesanal, Sennett irá tratar de questões relativas à motivação e ao talento. No penúltimo capítulo - O trabalho voltado para a qualidade - trata, portanto, de entender o desejo do Artífice pelo trabalho bem feito. Este desejo ou motivação relaciona-se, segundo o autor, às características de personalidade do Artífice. Ele tende a possuir uma energia obsessiva que o leva a uma busca intensa e constante por um trabalho de qualidade. Sennett destaca, contudo, que este desejo pessoal não se encontra desvinculado da organização social. As organizações são responsáveis por proporcionarem um ambiente que favoreça o uso positivo destas características, seja fortalecendo a capacitação do Artífice, seja contribuindo para que ele aprenda a gerir sua obsessão, "questionando-a e moderando-a” (p. 297). O autor acrescenta que não basta reconhecer e capacitar, tornando o trabalhador um especialista, são necessárias formas de gestão que favoreçam a sua socialização, por consequência, a transferência de conhecimento. 
O último capítulo, Habilidade, inicia com uma afirmação um tanto polêmica: a de que qualquer pessoa pode tornar-se um bom Artífice. Trazendo discussões sobre os testes de inteligência e sua capacidade real de avaliar as habilidades do Artífice, Sennett advoga a tese de que a aprendizagem dessas habilidades inicia-se na infância e é aprimorada pelos jogos infantis. Considera que é por meio do jogo que ocorre a apreensão de regras pelas crianças, que testam seus limites e vão apreendendo o mundo das coisas. Sendo assim, o fazer (trabalhar) nasce do brincar.

Sennett finaliza sua obra enfatizando três questões centrais relativas ao trabalho: 1) é ele que nos coloca no mundo e define as relações que estabelecemos; 2) este fazer não é neutro, nem os objetos que ele cria; e 3) é importante o orgulho pelo trabalho, mas ele não deve se constituir em uma cegueira. Desta forma, o autor deseja romper com a aura de inocência que rodeia o trabalho humano. Ele pode não ser para o bem comum, pode causar o mal, por isso, é necessário que o Artífice reflita constantemente sobre os aspectos éticos relativos ao seu trabalho.

Cremos que, apesar da tentativa de destrinçar as ideias centrais, somente a leitura integral do livro permitirá a compreensão de determinados pressupostos aqui colocados. A riqueza de detalhes do autor, que se utiliza também de uma linguagem expressiva e imaginativa, só pode ser percebida na leitura do mesmo.
O texto nos remete a uma reflexão sobre a relação ser humano-trabalho, em que "ser ou não ser um artífice" não parece tratar-se somente de uma questão, mas de algo essencial para trazer o sentimento de realização no trabalho e, portanto, essencial para a saúde mental do trabalhador. Tal reflexão perpassa pela necessidade da criação de ambientes de trabalho mais saudáveis, que favoreçam esta ligação afetiva (positiva) com o trabalho. Todos aqueles que se interessam pelas diferentes facetas do trabalho terão neste livro um campo fértil para reflexões e questionamentos.

\section{Referências}

SENNETT, R. A corrosão do caráter: conseqüências pessoais do trabalho no novo capitalismo. Rio de Janeiro: Record, 1998.

. Respect in a world of inequality. London: Penguin, 2002.

. A cultura do novo capitalismo. Rio de Janeiro: Record, 2006.

. A brief biography. 2008. Disponível em: <http://www.richardsennett.com/site/SENN/ Templates/General.aspx?pageid $=8>$. Acesso em: 20 nov. 2009.

\section{Agradecimentos}

A autora agradece a leitura e as discussões relativas ao livro e à presente resenha realizada pelo Professor Doutor Mário César Ferreira e demais colegas do Ecos - Núcleo de Ergonomia da Atividade, Cognição e Saúde/UnB.

Magali Costa Guimarães

Doutora em Psicologia e Professora do Centro Universitário de Brasília/UniCEUB - Brasília/DF

magalicostaguimaraes@hotmail.com 